\title{
Pigmented basal cell carcinoma: A rare clinical variant treated with excision and grafting
}

\author{
Manjunatha Puttaiah1, Deekshith Rajmohan², Shishira R. Jartarkar'1 \\ ${ }^{1}$ Department of Dermatology, Venereology and Leprosy, KVG Medical College and Hospital, Kurunjibhag, Sullia, India, \\ ${ }^{2}$ Department of Otorhinolaryngology, KVG Medical College and Hospital, Kurunjibhag, Sullia, India
}

Corresponding author: Dr. Shishira R. Jartarkar, E-mail: dr.shishira@gmail.com

\begin{abstract}
Basal cell carcinoma (BCC) is a most common malignant tumour of skin. It develops on sun-exposed skin of lighter skinned individuals. It is a slow growing, locally invasive tumor. It is rare in dark skin because of the inherent photoprotection of melanin and melanosomal dispersion. The frequency of pigmented variant of BCC can reach up to $6 \%$ of total BCC in Hispanics. A $62 \mathrm{yr}$ old female came with the complaint of hyperpigmented plaque over the right lateral wall of the nose at the osseo-cartilagenous junction since $2 y r s$ with evidence of central ulceration and bleeding. A wide local excision was planned with $5 \mathrm{~mm}$ margins and covered with a full thickness graft obtained from the right retroauricular area. Post operation photographs taken. BCC is the most common non-melanoma skin cancer in the world. Though, pigmented BCC is the rare variant, it is becoming increasingly common in Asian population. UV radiation is the most important preventable risk factor for BCC. With increasing awareness and advent of newer treatment modalities, better cosmetic outcome with improved survival are expected.
\end{abstract}

Key words: Pigmented BCC; Locally invasive; Wide local excision

\section{INTRODUCTION}

Basal cell carcinoma (BCC) is the most common skin cancer in humans. The malignancy accounts for $75 \%$ of all non-melanoma skin cancers. It develops on sun-exposed skin of lighter skinned individuals [1]. It is a slow growing, locally invasive tumor. It is rare in dark skin because of the inherent photo protection of melanin and melanosomal dispersion. Pigmented BCC is a rare clinical and histological variant of $\mathrm{BCC}$ that exhibits increased pigmentation. The frequency of pigmented $\mathrm{BCC}$ varies, being $6 \%$ of all the BCCs [2].

\section{CASE REPORT}

A 62year old female came with the complaint of asymptomatic darkly pigmented lesion over the right side of the nose since one year, initially small in size, measuring about $0.2 \times 0.2 \mathrm{cms}$, gradually progressed to the present size of $1 \times 1 \mathrm{cms}$. Patient gives history of spontaneous bleeding from the lesion. No history of significant loss of weight or appetite. On examination, a solitary, oval, well-defined, hyperpigmented plaque, measuring about IxI cm with irregular margins, surface showing area of ulceration, present over the right lateral wall of the nose, above the right ala (Fig. 1). No regional lymphadenopathy was noted. A differential diagnosis of pigmented basal cell carcinoma, keratoacanthoma, malignant melanoma was considered. A wide local excision with full thickness graft was planned (Fig. 2). Under aseptic precautions, after local infiltration of the lesion, an elliptical incision was placed with $0.5 \mathrm{~cm}$ margin all around the lesion and the tumor was removed in toto and sent for histo-pathological examination. A same sized full thickness graft was harvested from the right post auricular area and placed over the recipient site and sutured with no tension (Fig. 3). The margins of the biopsy specimen were marked and sent for histo-pathological examination which revealed that the tumor was arising near the basal layer consisting

\footnotetext{
How to cite this article: Puttaiah M, Rajmohan D, Jartarkar SR. Pigmented basal cell carcinoma: A rare clinical variant treated with excision and grafting. Our Dermatol Online. 2016;7(4):427-430.

Submission: 04.05.2016; Acceptance: 25.07.2016

DOI: 10.7241 /ourd.20164.117
}

(c) Our Dermatol Online 4.2016 
of large and small nests of basaloid cells (tumor cells) with peripheral palisading. The stroma showed the presence of melanophages and melanin interspersed

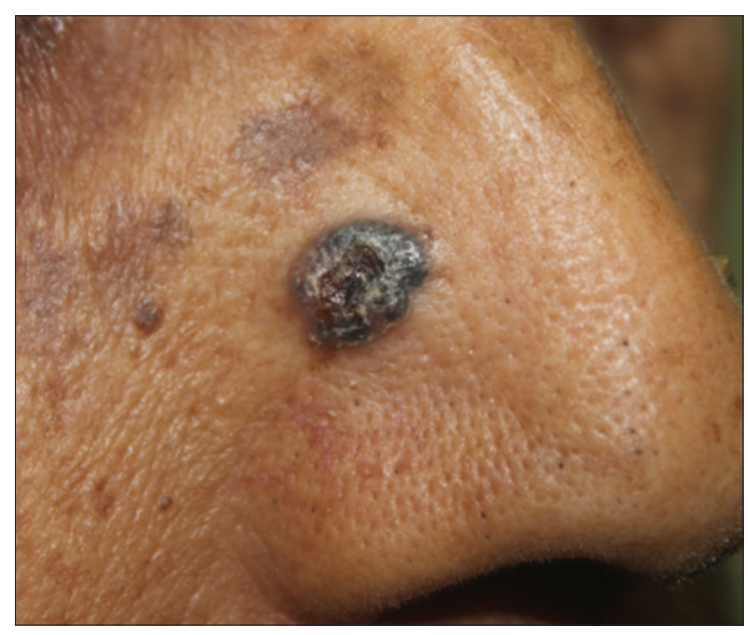

Figure 1: Hyper-pigmented plaque over right side of the nose.

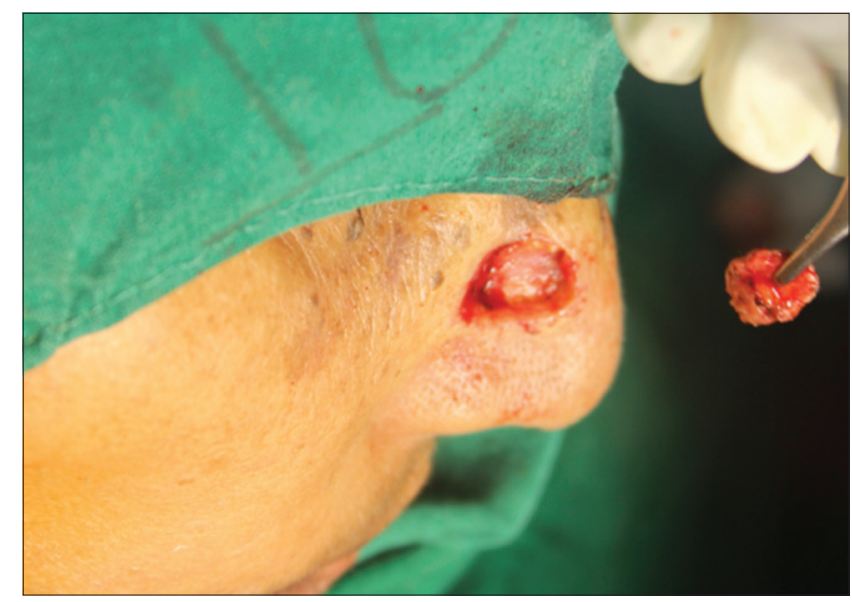

Figure 2: The tumor site after wide local excision.

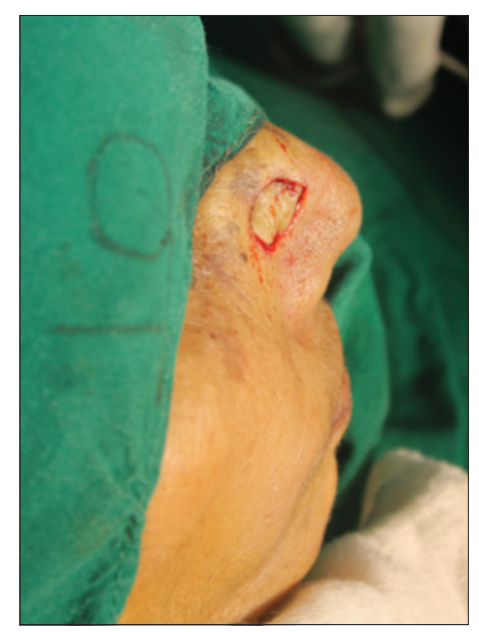

Figure 3: Intraoperative photograph showing the graft placement after wide excision of the tumor. amongst tumor cells along with lymphoplasmacytic infiltrate is seen. The tumor is seen extending from entire dermis upto the muscle. The lateral and deeper resected margins were free of tumor (Fig. 4).

At day 7 , the sutures were removed and the graft was taken up well (Fig. 5). Since, the resected border was free of the tumor residues, no further therapeutic intervention was undertaken and patient followed up regularly.

Prior to the study, patient gave written consent to the examination and biopsy after having been informed about the procedure.

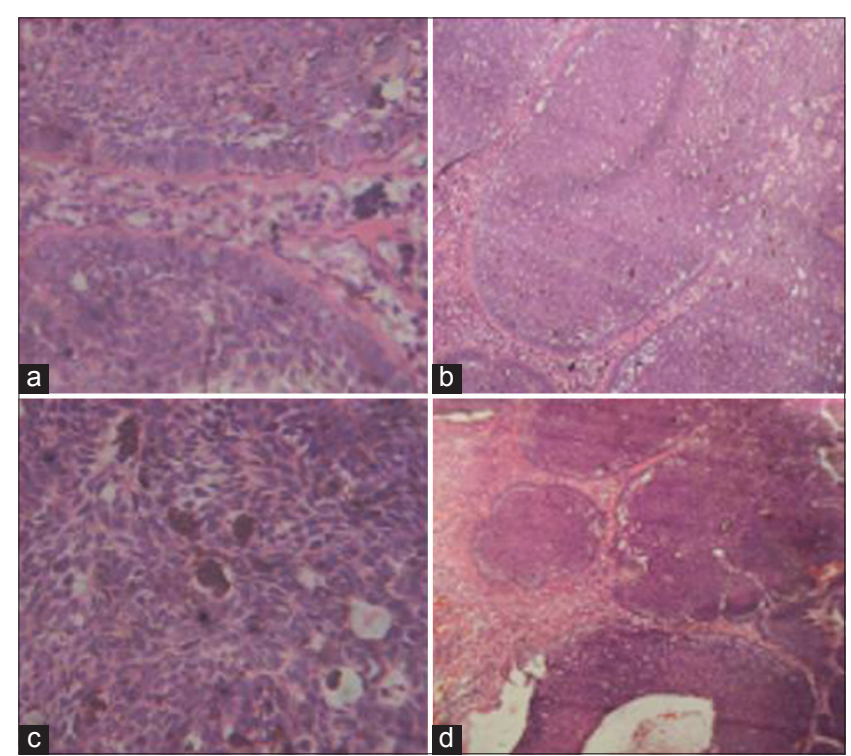

Figure 4: a) Palisaded arrangement of tumor cells ( $x 40), b)$ tumor nests with melanin pigment interspersed among tumor cells $(x 10), c)$ basaloid tumor cells with melanin and melanophages (x40), (d) tumor nests with peripheral palisading of the basaloid cells $(\mathrm{x} 4)$.

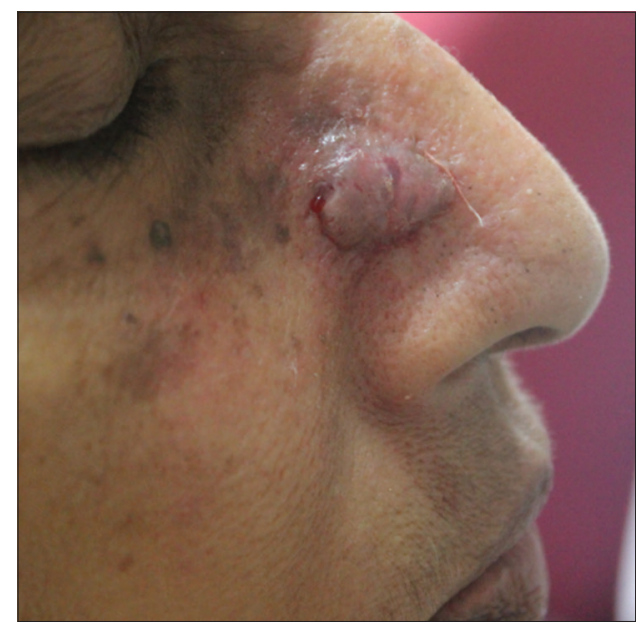

Figure 5: Postoperative day 8 with good take-up of the graft. 


\section{DISCUSSION}

BCC was first described in the year 1827 by Jacob [1]. The Basal cell carcinoma is a common malignant neoplasm of the skin, accounting for $75 \%$ of all the non-melanoma skin cancers. Pigmented basal cell carcinoma is a clinical and a histological variant of $\mathrm{BCC}$ which is characterized by brown or black pigmentation, comprising of $6 \%$ of total BCCs [2]. The tumor predominantly occurs on the sun-exposed areas of the skin. It is relatively rare in dark-skinned individuals. Head and neck is the most common site seen in about $85 \%$ of the patients. In the remaining $15 \%$, the tumor develops on the shoulder, back or chest. BCC is the most important malignant tumor involving the lower eyelid and as at other sites, exposure to sunlight is an important risk factor [3].

Ultraviolet (UV) radiation induces mutations in certain genes such as $\mathrm{p} 53$ gene for $\mathrm{BCC}$ and squamous cell carcinoma (SCC) and the patched (PTCHl) gene for BCC. It also causes alteration in substitution of the base at di-pyrimidine sites and induces inflammation via cyclooxygenase-2 pathway [4]. The other risk factors include exposure to ionizing radiations, arsenic and coal tar derivatives [5].

BCC is derived from the basaloid epithelium located in the follicular bulges, anagen hair bulbs and the follicular matrix cells. In adults, the cell of origin is believed to be pluripotent progenitor epithelial cells, resulting in diversity of histological patterns of BCC [6].

The clinical picture of $\mathrm{BCC}$ is variable. It can present as a papulonodular lesion with pearly translucent edge, as a plaque with variable pigmentation, as an ulcerated destructive lesion (rodent ulcer), an erythematous plaque or a cystic nodule. Aggressive tumors are larger with more frequent ulceration and can be locally destructive [7].

Histopathologically, BCCs share the following common features - predominant cell type is basaloid, with specialized stroma, predominant palisading of the lesional nucWlei and clefting artefact between epithelium and the stroma. Various morphological and histological subtypes have been defined. These include nodular (solid), micronodular, cystic, superficial (superficial multifocal), pigmented, adenoid, infiltrating, sclerosing, keratotic, infundibulo-cystic, metatypical, basosquamous and fibroepitheliomatous. The most common variant is nodular type, characterized by nodular masses of basaloid cells extending into the dermis. The tumor cells resemble those of basal layer of the epidermis, having relatively small amount of cytoplasm. The nuclei of the tumor cells are compact, darkly staining and closely set. The cytoplasm stains poorly and cell margins are indistinct. The characteristic feature is peritumoral lacunae or retraction clefts. Pigmented BCC is a variant of BCC showing increased melanin pigments which are produced by benign melanocytes colonizing the tumor [8]. Functional melanocytes are scattered throughtout the islands of tumors, with numerous melanophages in the stroma. There are melanosomes complexes in the tumor cells, as a result of repeated phagocytosis of melanosome containing tumor cells that have undergone apoptosis.

The primary treatment option for BCC is excision with atleast 3-6mm margins for small and well delineated tumors, as this achieves satisfactory tumor clearance of about $84.9 \%$. Surgical defects are repaired with primary closure, grafts, flaps or left to heal by secondary intention [9].

The other modalities of treatment include curettage and electrodessication, radiotherapy, Mohs' micrographic surgery (highest cure rate and greater tissue conservation), cryosurgery, photodynamic therapy and interferons. The topical modalities for low risk BCCs include 5-fluorouracil and imiquimod creams. Also, the patient should be advised regarding sunprotection, protective clothing and regular sunscreens [4].

\section{CONCLUSION}

$\mathrm{BCC}$ is the most common non-melanoma skin cancer in the world. Though, pigmented BCC is the rare variant, it is becoming increasingly common in Asian population. UV radiation is the most important preventable risk factor for BCC. With increasing awareness and advent of newer treatment modalities, better cosmetic outcome with improved survival are expected.

\section{REFERENCES}

1. Crowson AN. Basal cell carcinoma: Biology, morphology and clinical implications. Med Pathol. 2006;19:S127-47.

2. Deepadarshan K, Mallikarjun M, Abdu NN. Pigmented basal cell carcinoma: A clinical variant, report of two cases. J Clin Diagc Res. 2013;7:3010-11.

3. Saldanha P, Shantala PR, Upadhaya K. Cutaneous basal cell carcinoma: A morphological spectrum. Arch Med Health Sci. 2015;13:24-8. 


\section{www.odermatol.com}

4. Nouri K, Ballard CJ, Patel AR, Brasie RA. Basal cell carcinoma. In: Nouri K, editor. Skin Cancer, New York Mc Graw Hill. 2007;61-85.

5. Panda S. Non melanoma skin cancer in India: Current Scenario. Indian J Dermatol. 2010;55:373-8.

6. Dourmishev LA, Rusinova D, Botev I. Clinical variants, stages, and management of basal cell carcinoma. Indian Dermatol Online J. 2013;4:12-7.

7. Annessi G, Baliva G. Basal cell and squamous cell carcinomas. Clinico-histological features. Ann Ist Super Sanita. 1996;32:29-36.

8. Elder DE, Elenitsas R, Johnson BL, Murphy GF, Xu X. Basal cell carcinoma. In, Eider DE, editor. Histopathology of the skin. $10^{\text {th }}$ ed. Philadelphia: Lippincott Williams and Wilkins. 2009;823-35.
9. Goh BK, Ang P, Wu YJ, Goh CL. Characteristics of basal cell carcinoma amongst Asians in Singapore and a comparison between completely and incompletely excised tumors. Int J Dermatol. 2006;45:561-4.

Copyright by Manjunatha Puttaiah, et al. This is an open access article distributed under the terms of the Creative Commons Attribution License, which permits unrestricted use, distribution, and reproduction in any medium, provided the original author and source are credited.

Source of Support: Nil, Conflict of Interest: None declared. 